\title{
DETEKSI DAN PERHITUNGAN OBJEK BERDASARKAN WARNA MENGGUNAKAN COLOR OBJECT TRACKING
}

\author{
Dedy Agung Prabowo ${ }^{1}$, Dedy Abdullah ${ }^{2}$, Ari Manik ${ }^{3}$ \\ 1,2,3 Program Studi Informatika, Fakultas Teknik, Universitas Muhammadiyah Bengkulu \\ J1. Bali PO BOX 118 Telp (0736)227665’ FAX (0736)26161, Bengkulu 38119 \\ ${ }^{1}$ dedyagungprabowo@umb.ac.id \\ ${ }^{2}$ dedy_abdullah@umb.ac.id \\ 3 arimanikegmail.com
}

Abstrak: Perkembangan ilmu pengetahuan dan teknologi sekarang ini banyak menghasilkan alat-alat yang dapat membantu manusia dalam menyelesaikan pekerjaannya secara otomatis. Salah satu bidang ilmu yang mendukung dalam mempermudah pekerjaan manusia tersebut adalah computer vision. Masalah utama dalam computer vision adalah bagaimana mengenali gambar dan memanfaatkan gambar yang ditangkapnya. Tujuan dalam penelitian ini yaitu membangun system yang mampu mendeteki dan menghitung objek yang tertangkap oleh kamera berdasarkan warna. Hasil dari penelitian ini menunjukkan bahwa color object tracking dapat digunakan untuk mengenali dan menghitung warna yang ditentukan dengan kamera.

Kata Kunci: computer vision, kamera, object color tracking, pengolahan citra, deteksi warna

\begin{abstract}
The development of science and technology is now generated many tools that can help humans get things done automatically. One area of science that supports in this regard is computer vision. The main problem in computer vision is how to recognize the image and take advantage of the image. The purpose of this research is to build a system capable of detecting and counting objects caught by the camera based on color. The results of this study show that the color object tracking can be used to recognize and calculate the color specified by the camera. Keywords: computer vision, camera, object color tracking, image processing, color detection
\end{abstract}

\section{PENDAhUlUAN}

Perkembangan ilmu pengetahuan dan teknologi sekarang ini banyak menghasilkan alat-alat yang dapat membantu manusia dalam menyelesaikan pekerjaannya secara otomatis. Salah satu bidang ilmu yang mendukung dalam mempermudah pekerjaan manusia tersebut adalah computer vision.
Salah satu perkembangan dari penggunaan teknik computer vision adalah tracking objek (pelacakan objek). Pelacakan objek bertujuan untuk mendeteksi dan mengikuti posisi dari suatu objek bergerak yang diinginkan. Tracking objek banyak dibutuhkan oleh berbagai macam aplikasi vision based seperti human computer interface, kompresi/ komunikasi video dan sistem keamanan. Tracking objek mampu mendeteksi objek yang bergerak, memfilter noise, dan gerakan-gerakan lain yang tidak diperlukan. Banyak cara yang dilakukan untuk melacak suatu objek, cara yang paling populer melakukan pelacakan dengan menggunakan warna RGB sebagai tolak ukur pendeteksian. Dikarenakan warna RGB adalah salah satu warna dasar segala objek dalam kehidupan sehari-hari dan juga warna yang sering digunakan dalam bidang pengolahan citra digital. 
Jurnal Pseudocode, Volume V Nomor 2, September 2018, ISSN 2355-5920 www.ejournal.unib.ac.id/index.php/pseudocode

\section{DASAR TEORI}

\section{A. Citra}

Pengertian citra secara umum adalah merupakan suatu gambar, foto ataupun berbagai tampilan dua dimensi yang menggambarkan suatu visualisasi objek. Citra dapat diwujudkan dalam bentuk tercetak ataupun digital. Citra digital adalah larik angka-angka secara dua dimensional. Citra digital tersimpan dalam suatu bentuk larik (array) angka digital yang merupakan hasil kuantifikasi dari tingkat kecerahan masing-masing piksel penyusun citra tersebut.

Ditinjau dari sudut pandang matematis, citra merupakan fungsi menerus (continue) dari intensitas cahaya pada bidang dwimatra. Sumber cahaya menerangi objek, objek memantulkan kembali sebagian dari berkas cahaya tersebut. Pantulan cahaya ini ditangkap oleh alat-alat optik, misalnya mata pada manusia, kamera, scanner dan lain sebagainya sehingga bayangan objek yang disebut citra tersebut terekam [1].

Citra digital yang tersimpan dalam larik dua dimensi tersusun atas unsur-unsur kecil yang disebut dengan piksel. Masing-masing piksel terkait secara spasial dengan area di permukaan bumi. Struktur array ini tersusun dalam baris horisontal yang disebut baris (lines) dan kolom vertikal (samples). Masing-masing piksel dalam raster citra menyimpan nilai tingkat kecerahan piksel yang diujudkan sebagai suatu angka digital. Susunan piksel dalam struktur array citra digital yang tersebut disebut dengan data raster.Sebagai suatu susunan dari angka digital, beberapa bentuk operasi matematis dapat diberlakukan terhadap citra digital tersebut.

\section{B. Pixel, Resolusi, Intensitas}

Suatu gambar yang ada di dalam komputer sesungguhnya adalah kumpulan dari ribuan titik yang sangat kecil dan tiap-tiap titik tersebut memiliki warna tertentu. Kotak-kotak kecil itulah yang disebut pixel, ukuran suatu citradinyatakan dalam titik atau pixel [2]. Setiap pixel mempunyai satu warna dan bergabung dengan pixel-pixel lainnya sehingga membentuk suatu pola dan menghasilkan gambar.

Jumlah pixel per daerahnya disebut dengan resolusi. Resolusi itulah yang menentukan kualitas dari gambar. Jika suatu gambar diperbesar, makaresolusi gambar akan menjadi kecil dan gambar menjadi tidak tajam. Semakin tinggi resolusi gambar, maka akan semakin tinggi kemampuan perbesarannya.

Pixel yang membentuk suatu gambar memiliki warna-warna tertentu. Jumlah warna yang dimiliki suatu gambar disebut intensitas.Intensitas gambar mempunyai beberapa jenis istilah yaitu 256 warna, high color, 16 juta warna (true color), gradasi abuabu (grayscale), dan hitam-putih (black \& white).

Semakin banyak jumlah warna dalam suatu gambar maka akan semakin bagus. Jumlah warna maksimum dari gambar dapat dilihat dari jenis (ekstensi) filenya. File gambar berekstensi .jpg memiliki jumlah warna maksimum 16 juta warna, file gambar berekstensi gif memiliki jumlah warna maksimum 265 warna.

\section{Model Warna RGB}

RGB adalah suatu model warna yang terdiri atas 3 buah warna: merah (red), hijau (green), dan biru (blue), yang ditambahkan dengan berbagai cara untuk menghasilkan bermacam-macam warna [2]. 
Jurnal Pseudocode, Volume V Nomor 2, September 2018, ISSN 2355-5920

www.ejournal.unib.ac.id/index.php/pseudocode

Model warna RGB adalah model warna berdasarkan konsep penambahan kuat cahaya primer yaitu red, green dan blue. Dalam suatu ruang yang sama sekali tidak ada cahaya, maka ruangan tersebut adalah gelap total. Tidak ada signal gelombang cahaya yang diserap oleh mata kita atau RGB (0, 0, 0). Apabila kita menambahkan cahaya merah pada ruangan tersebut, maka ruangan akan berubah warna menjadi merah misalnya RGB $(255,0,0)$, semua benda dalam ruangan tersebut hanya dapat terlihat berwarna merah. Demikian apabila cahaya kita ganti dengan hijau atau biru.

Seperti yang diketahui tahu bahwa RGB atau Red, Green, Blue merupakan sistem pewarnaan untuk digital appearance dan banyak sekali digunakan untuk monitor komputer, video, layar ponsel dll. Sistem warna RGB terdiri dari $100 \%$ Red, $100 \%$ Green dan $100 \%$ Blue yang menghasilan $100 \%$ putih. Tidak ada hitam di RGB.

Apabila kita melanjutkan percobaan memberikan 2 macam cahaya primer dalam ruangan tersebut seperti (merah dan hijau), atau (merah dan biru) atau (hijau dan biru), maka ruangan akan berubah warna masing-masing menjadi kuning, atau magenta atau cyan. Warnawarna yang dibentuk oleh kombinasi dua macam cahaya tersebut disebut warna sekunder.

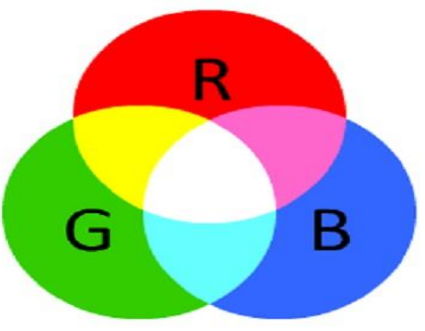

Gambar 1. Warna RGB

\section{Pengolahan Citra}

Pengolahan citra digital adalah manipulasi dan interprestasi digital dari citra dengan bantuan komputer. Input dari pengolahan citra adalah citra, sedangkan outputnya adalah citra hasil pengolahan [3].

Istilah pengolahan citra digital secara umum didefinisikan sebagai pemrosesan citra dua dimensi dengan komputer. Dalam definisi yang lebih luas, pengolahan citra digital juga mencakup semua data dua dimensi. Citra digital adalah barisan bilangan nyata maupun kompleks yang diwakili oleh bit-bit tertentu.

Operasi-operasi pada pengolahan citra diterapkan bila:

1. Perbaikan atau memodifikasi citra dilakukan untuk meningkatkan kualitas penampakan citra/menonjolkan beberapa aspek informasi yang terkandung dalam citra (image enhancement). Contoh: perbaikan kontras gelap/terang, perbaikan tepian objek, penajaman, pemberian warna semu, dll.

2. Adanya cacat pada citra sehingga perlu dihilangkan/ diminimumkan (image restoration). Contoh: penghilangan kesamaran (debluring) citra tampak kabur karena pengaturan fokus lensa tidak tepat / kamera goyang, penghilangan noise.

3. Elemen dalam citra perlu dikelompokkan, dicocokan atau diukur (image segmentation). Operasi ini berkaitan erat dengan pengenalan pola.

4. Diperlukannya ekstraksi ciri-ciri tertentu yang dimiliki citra untuk membantu dalam pengidentifikasian objek (image analysis). Proses segementasi kadangkala diperlukan untuk melokalisasi objek yang diinginkan dari sekelilingnya. Contoh: pendeteksian tepi objek. 
Jurnal Pseudocode, Volume V Nomor 2, September 2018, ISSN 2355-5920

www.ejournal.unib.ac.id/index.php/pseudocode

5. Sebagian citra perlu digabung dengan bagian citra yang lain (image reconstruction). Contoh: beberapa foto rontgen digunakan untuk membentuk ulang gambar organ tubuh.

6. Citra perlu dimampatkan (image compression) Contoh: suatu file citra berbentuk BMP berukuran $258 \mathrm{~KB}$ dimampatkan dengan metode JPEG menjadi berukuran $49 \mathrm{~KB}$.

7. Menyembunyikan data rahasia (berupa teks/citra) pada citra sehingga keberadaan data rahasia tersebut tidak diketahui orang (steganografi dan watermaking).

\section{E. Computer Vision}

Computer vision (visi komputer) dapat didefinisikan dengan pengertian pengolahan citra yang dikaitkan dengan akuisisi citra, pemrosesan, klasifikasi, penganan, dan pencakupan keseluruhan, pengambilan keputusan yang diikuti pengidentifikasian citra. Inti dari teknologi Computer Vision adalah untuk menduplikasi kemampuan penglihatan manusia ke dalam benda elektronik sehingga benda elektronik dapat memahami dan mengerti arti dari gambar yang dimasukkan [4].

Sebagai suatu disiplin ilmu, visi komputer berkaitan dengan teori di balik sistem buatan bahwa ekstrak informasi dari gambar. Data gambar dapat mengambil banyak bentuk, seperti urutan video, pandangan dari beberapa kamera, atau data multi-dimensi dari scanner medis.

Sebagai disiplin teknologi, visi komputer berusaha untuk menerapkan teori dan model untuk pembangunan sistem visi komputer. Contoh aplikasi dari visi komputer mencakup sistem untuk:

1. Pengendalian proses (misalnya, sebuah robot industri atau kendaraan otonom).
2. Mendeteksi peristiwa (misalnya, untuk pengawasan visual atau orang menghitung).

3. Mengorganisir informasi (misalnya, untuk pengindeksan database foto dan gambar urutan).

4. Modeling benda atau lingkungan (misalnya, inspeksi industri, analisis citra medis).

5. Interaksi (misalnya, sebagai input keperangkat untuk interaksi komputer-manusia).

Sub-domain dari visi komputer termasuk adegan rekonstruksi, deteksi event, pelacakan video, pengenalan objek, belajar, indexing, estimasi gerak, dan pemulihan citra.

\section{F. Pelacakan Objek (Object Tracking)}

Tracking secara harfiah memiliki arti mengkuti jalan, atau dalam arti bebasnya ialah suatu kegiatan untuk mengikuti jejak suatu objek.Sistem pelacakan adalah suatu sistem yang mampu melacak atau mencari suatusuatu hal dengan memberikan informasi tentang hal tersebut. Dalam bidang pengolahan citra teknik pelacakan sering kali diimplementasikan guna membantu kegiatan manusia dimana diperlukannya suatu sistem yang mampu melacak objek secara otomatis. Beberapa faktor yang sering kali mengganggu pelacakan objek adalah sebagai berikut [5].

1. Hilangnya informasi dikarenakan projeksi 3 dimensi dalam citra 2 dimensi.

2. Noise pada citra.

3. Nonrigid atau artikulasi alami pada objek.

4. Objek terhalang suatu benda.

5. Bentuk objek yang rumit.

6. Perubahan drastis pencahayaan.

7. Persyaratan pengolahaan secara Real-Time. Pada dasarnya teknik pelacakan objek memerlukan suatu fitur pada objek yang ingin dilacak yang akan menjadi suatu acuan pelacakan. 
Jurnal Pseudocode, Volume V Nomor 2, September 2018, ISSN 2355-5920

www.ejournal.unib.ac.id/index.php/pseudocode

Seperti warna, bentuk, ataupun perbandingan frame 1 ke frame yang berikutnya. Berikut adalah dasar skema/ prosedur pelacakan objek.

\section{G. Webcam}

WebCam adalah sebuah periferal berupa kamera sebagai pengambil citra/gambar dan mikropon (optional) sebagai pengambil suara/audio yang dikendalikan oleh sebuah komputer atau oleh jaringan komputer. Sebuah webcam dapat dibangun suatu sistem keamanan dengan video streaming yang dapat memantau secara real-time [6].

Gambar yang diambil oleh WebCam ditampilkan ke layar monitor, karena dikendalikan oleh komputer maka ada interface atau port yang digunakan untukmenghubungkan WebCam dengan komputer atau jaringan. Ada beberapa orang mengartikan WebCam sebagai Web pages + camera, karena dengan menggunakan WebCam untuk mengambil gambar video secara aktual bisa langsung di-upload bila komputer yang mengendalikan terkoneksi internet.

\section{METODE RISET}

Untuk mendukung penelitian yang dilakukan, penulis melakukan perancangan sistem sesuai dengan kebutuhan, yaitu dimulai dari tahapan Flowchart dan Rancangan Aplikasi.

Adapun flowchart dalam penerapan aplikasi terlihat pada gambar di bawah ini.

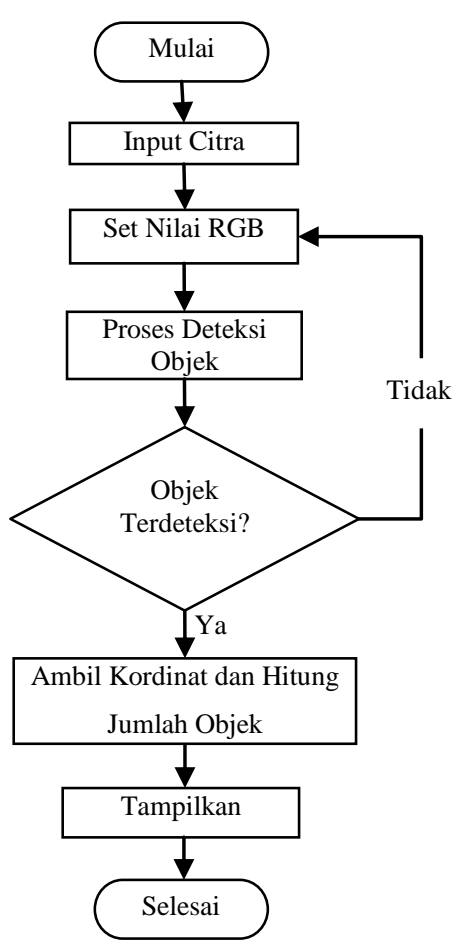

Gambar 2. Flowchart System

\section{HASIL DAN PEMBAHASAN}

\section{A. Tampilan Utama Aplikasi}

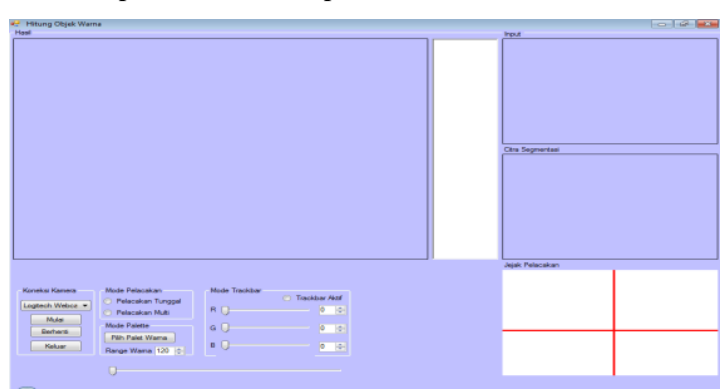

Gambar 3. Tampilan Utama Aplikasi

Penelitian dilakukan dengan penangkapan citra melalui webcam yang hasilnya akan ditampilkan pada salah satu bagian form aplikasi, nilai warna yang akan dideteksi sesuai dengan yang akan kita uji dapat ditentukan melalui pergeseran trackbar. Pelacakan dapat dilakukan secara tunggal maupun secara multi. Berikut contoh input dari tangkapan perangkat webcam. 
Jurnal Pseudocode, Volume V Nomor 2, September 2018, ISSN 2355-5920 www.ejournal.unib.ac.id/index.php/pseudocode

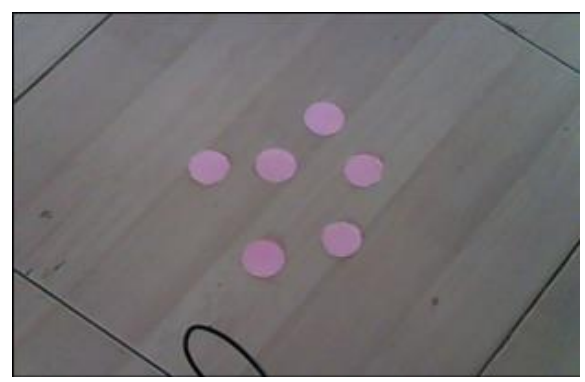

Gambar 4. Input Webcam

Input dari Webcam yang didapatkan akan digunakan pada proses segmentasi (filtering) untuk memisahkan warna yang ingin di deteksi dengan backgroundnya. Hasil Segmentasi dari gambar diatas dapat dilihat pada Gambar 5 di bawah ini

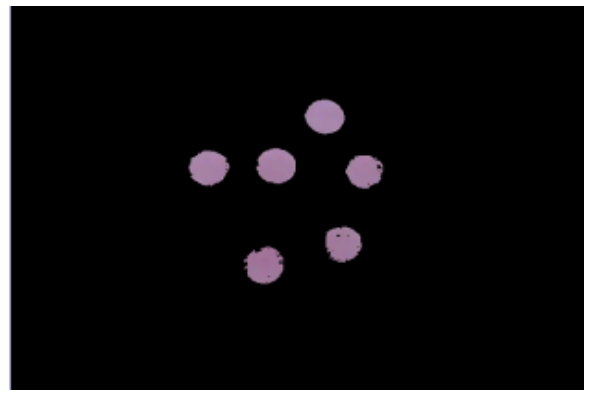

Gambar 5. Hasil filtering

Hasil dari filtering yang didapatkan akan digunakan untuk menentukan region tempat objek tersebut berada sehingga dapat diketahui lokasi dan dapat ditandain dengan area kotak sebagai tanda terlacaknya object tersebut sekaligus menghitung jumlah object yang telah terdeteksi. Hasil dari proses ini dapat dillihat pada gambar 6 . di bawah ini.

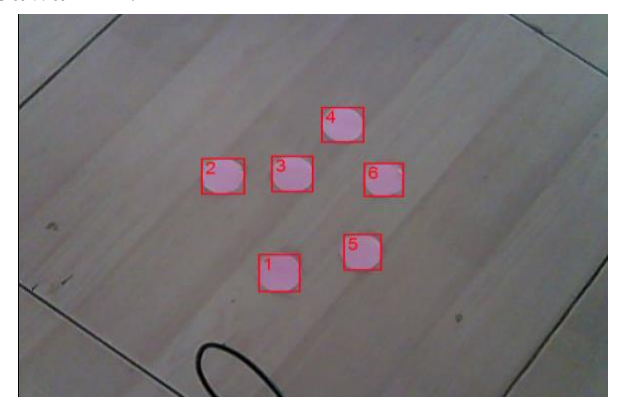

Gambar 6. Hasil Deteksi dan Perhitungan objek

\section{A. Pengujian Program}

1. Pengujian Warna Objek dan Latar Belakang
Pengujian dilakukan dengan mengubah warna objek dengan latar belakang abu-abu untuk mengetahui warna apa saja yang dapat dideteksi oleh sistem.

Tabel 1. Hasil Pengujian Berbagai Warna Objek dan Latar Belakang Abu-abu

\begin{tabular}{|c|c|c|}
\hline Warna & Terlacak? & Keterangan \\
\hline $\begin{array}{l}\text { Objek } \\
\text { (Merah) } \\
\begin{array}{l}\text { Latar Belakang } \\
\text { (abu-abu) }\end{array}\end{array}$ & $\mathrm{Ya}$ & Sukses Terlacak \\
\hline $\begin{array}{l}\text { Objek } \\
\text { (Biru) } \\
\text { Latar Belakang } \\
\text { (Abu-abu) }\end{array}$ & $\mathrm{Ya}$ & Sukses Terlacak \\
\hline $\begin{array}{l}\text { Objek } \\
\text { (Hijau) } \\
\begin{array}{l}\text { Latar Belakang } \\
\text { (Abu-abu) }\end{array}\end{array}$ & $\mathrm{Ya}$ & Sukses Terlacak \\
\hline $\begin{array}{l}\text { Objek } \\
\text { (Putih) } \\
\begin{array}{l}\text { Latar Belakang } \\
\text { (Abu-abu) }\end{array}\end{array}$ & $\mathrm{Ya}$ & $\begin{array}{l}\text { Sukses Terlacak } \\
\text { Dengan lebih } \\
\text { banyak noise }\end{array}$ \\
\hline $\begin{array}{l}\text { Objek } \\
\text { (Abu-abu gelap) } \\
\text { Latar Belakang } \\
\text { (Abu-abu) }\end{array}$ & Tidak & $\begin{array}{l}\text { Gagal Terlacak } \\
\text { dikarenakan } \\
\text { range warna } \\
\text { yang nyaris } \\
\text { serupa. }\end{array}$ \\
\hline
\end{tabular}

Pada Tabel 1 di atas dapat dinyatakan bahwa perbedeaan antara warna objek dan warna latar belakang mempengaruhi hasil yang didapatkan. Objek yang tidak dapat dibedakan oleh system karena warna latar belakang masuk dalam range warna objek yang telah ditentukan sehingga system tidak dapat membedakan antara objek dan latar belakang yang menyebakan proses pelacakan terganggu atau bahkan menjadi gagal.

2. Pengujian dengan pencahayaan yang berbeda

Pengujian dilakukan dengan beberapa kondisi pencahayaan lingkungan dimana nilai satuan cahaya yang digunakan adalah luminosity atau lux. Cahaya dihitung dengan menggunakan alat bantu android dengan aplikasi light meter. 
Tabel 2. Hasil Deteksi Objek dengan Pencahayaan yang Berbeda

\begin{tabular}{|c|c|c|c|}
\hline $\begin{array}{c}\text { Nilai } \\
\text { Cahaya }\end{array}$ & $\begin{array}{c}\text { Kondisi } \\
\text { Lingkungan }\end{array}$ & Hasil Proses & Pengaruh \\
\hline $0 \operatorname{lu} x$ & Gelap & & $\begin{array}{l}\text { Tidak adanya cahaya } \\
\text { mempengaruhi sistem } \\
\text { sehingga hasil } \\
\text { tangkapan citra menjadi } \\
\text { sangat buruk dengan } \\
\text { framerate yang sangan } \\
\text { buruk }\end{array}$ \\
\hline $\begin{array}{l}1 \quad \operatorname{lu} x-30 \\
\operatorname{lux}\end{array}$ & Samar-Samar & & $\begin{array}{l}\text { Minimnya cahaya } \\
\text { mempengaruhi sistem } \\
\text { sehingga hasil kualitas } \\
\text { tangkapan citra menjadi } \\
\text { buruk dengan framerate } \\
\text { yang masih buruk }\end{array}$ \\
\hline $\begin{array}{l}31 \text { lux }- \\
15000 \\
\operatorname{lux}\end{array}$ & Terang & $\begin{array}{r}00 \\
10\end{array}$ & $\begin{array}{lr}\text { Nilai cahaya } & \text { yang } \\
\text { sangat ideal } & \text { untuk } \\
\text { penelitian } & \text { yang } \\
\text { menggunakan } & \text { webcam } \\
\text { sebagai } & \text { inputnya } \\
\text { sehingga } & \text { framerate } \\
\text { yang dihasilkan baik. }\end{array}$ \\
\hline $\begin{array}{l}>15000 \\
\operatorname{lux}\end{array}$ & Sangat Terang & & $\begin{array}{l}\text { Kelebihan cahaya } \\
\text { membuat sistem dengan } \\
\text { webcam beresolusi } 5 \\
\text { mp tidak mampu } \\
\text { menangkap citra dengan } \\
\text { dengan baik }\end{array}$ \\
\hline
\end{tabular}

\section{PENUTUP}

\section{A. Kesimpulan}

Kesimpulan pada penelitian ini yaitu:

1. Sistem yang dibuat dapat mendeteksi dan menghitung Objek yang telah ditentukan.

2. Perbedaan warna objek dan latar belakang objek sangat menentukan keberhasilan pendeteksian objek.

3. Pencahayaan yang baik untuk pendeteksian objek adalah 31- 15.000 lux.

\section{B. Saran}

1. Menambahkan algoritme lain agar pelacakan menjadi lebih stabil.

2. Mengimplementasikan sistem pada suatu mesin.

\section{REFERENSI}

[1] Shofwatul Uyun, (2008) Beberapa Aplikasi dari Pengolahan Citra Digital. /Jurnal/Fihris/Fihris Vol. III No.1 Januari - Juni 2008

[2] Hestiningsih, Idhawati, Pengolahan Citra, Teknik Informatika.2008.

[3] Sutoyo T, dkk. 2009 Teori pengolahan citra digital, Yogyakarta : Andi Publisher.

[4] Milan Sonka, Vaclav Hlavac, Roger Boyle, "Image Processing, Analysis, and Machine Vision", 2nd Edition, Thompson Publication, 2007.

[5] A. Yilmaz, O. Javed, and M. Shah, Object Tracking: A Survey, ACM Journal of Computing Surveys, Vol. 38, No. 4, 2006.

[6] Kartika Firdausy, Selamat Riyadi, Tole Sutikno, Muchlas, 2008, Aplikasi Webcam Untuk Sistem Pemantauan Ruang Berbasis Web, Jurnal TELKOMNIKA Vol 6 No.1 2008 